\title{
ALGUMAS REFLEXÕES SOBRE A PESSOA PORTADORA DE DEFICIÊNCIA E SUA RELAÇÃO COM O SOCIAL
}

\author{
Denise Teresinha da Rosa Quintão \\ Centro Clínico Thiago Würth - Instituto Pestalozzi - Canoas/RS
}

RESUMO:O presente trabalho buscará refletir sobre algumas questões que tratam das dificuldades de inclusão social da pessoa portadora de deficiência a partir do exame de alguns mecanismos de exclusão compartilhados pelo social. Os dispositivos construídos pela sociedade para a inclusão da diferença não tem sido suficientes para dar conta do mal-estar produzido por aqueles que carregam insígnias que denunciam a ruptura dos ideais narcísicos de perfeição. Neste artigo, pretende-se levantar apenas alguns questionamentos que possam contribuir para a problematização de um tema que vem sendo abordado de forma incipiente pela sociedade em suas diferentes instâncias, cujo debate tem sido precipitado pela demanda de adequação às leis que visam preservar espaços de inclusão à pessoa com deficiência e avançado à medida em que se torna necessário a revisão ou mesmo a construção das práticas de inclusão.

PALAVRAS-CHAVE: portador de deficiência, diferença, inclusão social, mecanismos de exclusão

\section{SOME REFLEXIONS ABOUT THA HANDICAPPED AND THEIR RELATION WITH THE SOCIAL}

ABSTRACT: This study will enquire about issues related to the difficulties encountered regarding the social inclusion of the handicapped. It is based on the examination of some exclusion mechanisms which are part of the social. The devices constructed by the society for the inclusion of the difference have not been sufficient to deal with the uneasiness produced by those who carry marks which denounce the rupture of the narcissistic ideals of perfection. In this article, it is intended to raise only some issues which can contribute to think trough about a matter that has been approached with incipient manner by the society in its differente instances. The social debate has been premature as a result of the demand of adjustment to the laws which aim to preserve the inclusion spaces for the handicapped and advanced when it becomes necessary the revision or even the construction of inclusion practices.

KEY-WORDS: handicapped, difference, social inclusion, exclusion mechanisms.

Na contemporaneidade, encontramo-nos imersos em discursos que trazem em seu bojo alguns ideais sociais que se transformam em imperativos, mesmo que não saibamos muito bem o que fazer com eles. Sem dúvida, muitos destes ideais se constituem a partir da análise dos sintomas sociais com os quais nos deparamos, cujas providências passam por diferentes dispositivos ativados pela sociedade, dentre eles, a criação de leis que possam promover soluções para as questões que nos afligem. Exemplos disso seriam a criação do ECA - Estatuto da Criança e do Adolescente (Lei No8.069 de 13 de julho de 1990) e o sancionamento da Lei Federal que redireciona o modelo assistencial em saúde mental às pessoas portadoras de transtornos mentais (Lei No 10.216 de 06 de abril de 2001), ambos resultado de um processo de discussão sobre problemas que perpassam, nestes casos, os temas da violência contra a criança e o adolescente e os direitos a serem assegurados a estes sujeitos e a questão da reclusão como prática terapêutica, porém segregacionista, ao "doente mental".

Porém, mesmo considerando-se a pertinência das leis, isso não nos garante efeitos imediatos, pelo contrário, sua viabilidade dependerá de uma rede complexa que exigirá de todos os envolvidos, direta ou indiretamente, uma (re)posição, à medida em que passa a revisar as referências que fundamentam os conceitos e os preconceitos de uma sociedade sobre determinada questão, assim como é preciso considerar, também, os aspectos políticos, econômicos, institucionais, etc., que estão em jogo.

Um termo caro em nossos dias, mas que corre riscos de banalização, diz respeito à inclusão. Tornou-se imperativo falar de inclusão, apesar de nem sempre termos discutido suficientemente sua contrapartida, que envolveria os mecanismos de exclusão social. É curioso o que se observa, pois quem exclui são sempre os outros e quem se propõe a incluir tende a receber um reconhecimento social, ainda que os artifícios utilizados não estejam muito claros e que em suas práticas estejam engendrados os 
princípios da exclusão.

Em se tratando da pessoa com deficiência , foco de interesse deste artigo, num ponto de vista, importantes conquistas vêm sendo constatadas. A atual Lei de Diretrizes e Bases da Educação Nacional (Lei No 9.394 de 20 de dezembro de 1996), prevê a garantia de vagas na escola regular para educandos portadores de necessidades especiais desde a educação infantil, assim como contempla a compra de vagas pelos governos em escolas especiais, instituições privadas sem fins lucrativos, para os casos que necessitam de uma condição de ensino especializado - não entraremos, aqui, no assunto bastante debatido atualmente no campo da educação acerca do papel da escola especial, pois este requer ser problematizado com maior atenção e à luz das diferentes disciplinas que se ocupam dos sujeitos em questão. No campo do trabalho, também encontramos dispositivos legais que visam garantir ao portador de deficiência um espaço no mercado de trabalho pela via da empregabilidade (Lei No 8.213 de 24 de julho de 1991), reservando um percentual de cotas proporcionalmente ao número de funcionários de uma empresa...

Entretanto, o que se constata é uma imensa dificuldade da sociedade para efetivar suas proposições, verificando-se a necessidade de uma constante revisão de suas práticas inclusivas, por vezes excludentes e discriminatórias. Não basta "estar dentro" - da escola, das instituições, da empresa, dos espaços públicos e privados - para haver inclusão. Os princípios da exclusão encontram-se imbuídos nas relações.

Para melhor clareza das idéias apresentadas neste artigo, torna-se importante dizer que o tema abordado parte de questões provenientes do trabalho como psicóloga em uma ONG e que emergem da escuta clínica e institucional de crianças, adolescentes e adultos jovens, portadores de transtorno psíquico (autismo, psicose), quadros orgânicos decorrentes de síndromes e de doenças congênitas, sendo a clientela atendida, em sua maioria, portadora de deficiência mental. Estas "marcas" - aparentes ou não - tendem a produzir uma inscrição importante na vida destes sujeitos, os quais, desde cedo, se vêem jogados diante do desafio de aprender a fazer um bom uso de suas insígnias a fim de enfrentar a vida e suas vicissitudes, buscando "brechas" possíveis para ocupar um lugar no mundo como sujeitos e como cidadãos.

Podemos ilustrar alguns dos problemas em que as práticas de inclusão se vêem imbricadas com as demandas sociais dos "tempos modernos" com algumas situações observadas no cotidiano das instituições, tomando-se como exemplo aquelas que objetivam a preparação para o trabalho de sujeitos portadores de deficiência, onde empresas, para aten- der à exigência da lei e preencher suas cotas de empregados com pessoas com deficiência, eventualmente buscam "portadores", preferencialmente, que portem, carreguem no corpo a marca da diferença. A pergunta: “Tem um Down?" faz eco. Poderíamos nos indagar que uso possa ser feito desta imagem. É preciso considerar que a modernidade inaugurou a era do marketing, sendo a imagem um recurso expressivo.

Também devemos levar em conta que, no terreno empresarial, um discurso bastante atual contempla a questão da responsabilidade social das empresas, aspecto que tende a lhes conferir um lugar de reconhecimento na cultura. Isso, por um lado, tem contribuído para o desenvolvimento de programas que visem o investimento em causas que tragam benefícios à sociedade, dentre eles, o desenvolvimento de projetos que buscam a inclusão social de pessoas com deficiência. Por outro lado, é sabido que tais iniciativas, caso não estejam norteadas por uma ética, podem assumir um caráter perverso, atendendo estritamente a interesses econômico-capitalistas.

Em evento em que participavam representantes de instituições que trabalham com portadores de diferentes tipos de deficiência e que debatiam sua inclusão nas organizações, surge, na platéia, uma pergunta: o que fazer frente ao choque e ao constrangimento produzido diante de um portador que tem seu corpo defeituoso? Uma resposta, produzida por um palestrante, sugeria que não olhemos para o corpo, mas que se mantenha o olhar fixo nos olhos de um portador. É preciso apagar a imagem do corpo imperfeito. Com isso nega-se, inclusive, a possibilidade de se reconhecer ali um sujeito, convocado socialmente a responder na mira da alienação ao olhar do outro.

Certamente que alguns avanços na direção de uma prática inclusiva em relação ao portador de deficiência vêm acontecendo, à medida em que tem sido promovidos espaços para debate e trocas de experiências no campo da educação, da saúde, da questão da acessibilidade aos espaços públicos e privados... Mas os discursos que circulam tanto no interior das instituições quanto para além de seus portões denunciam as fraturas de seus ideais, cujas boas intenções ainda se fundamentam, em muitas situações, na compaixão e na benfeitoria, herdeiras dos ideais filantrópico/iluministas.

Verifica-se, ainda nesta direção, a realidade de que a maioria das ONGs que se ocupam com os segregados sociais necessitam, para sua manutenção, do apoio financeiro da comunidade, através de eventos beneficientes ou mesmo resultado de serviços de tele-marketing e de doações para realizar seu trabalho, contando com a sensibilidade e o sentimento de caridade, revestidos de solidariedade, termo melhor 
aceito em nossos dias. Evidentemente que isso traduz um sintoma importante na organização de nossa sociedade, pois as verbas provenientes das autoridades governamentais - a princípio, "garantidas" por lei custam a chegar, com freqüência somente após vários meses de prestação de serviços, comprometendo o funcionamento das instituições e, quando chegam, são insuficientes, pois os valores contratados costumam não dar conta dos custos relativos ao trabalho desenvolvido, revelando uma desvalorização das instâncias oficiais para com seus excluídos.

Eizirik (2002, p. 73), a fim de compreender $o$ que é a sociedade, enfoca o poder enquanto conceito fundamental, referindo-se que este produz saber, gera discursos e práticas, constitui formas de subjetivação. Busca em Foucault elementos que apontam para a compreensão da constituição do sujeito contemporâneo e coloca que, para este autor, o sujeito não é uma substância que se constitui quando transcende a si mesmo através de sua atividade intencional (Eizirik, 2002, p. 91) e cita Foucault:

...o sujeito se constitui através de práticas de assujeitamento, ou, de uma forma mais autônoma, através de práticas de liberação, de liberdade (...) a partir certamente de um certo número de regras, estímulos, convenções que encontramos no meio cultural (Foucault In.: Eizirik, 2002, p. 91).

Eizirik (2002, p. 88) coloca que o termo "sujeito" sustenta sua constituição no campo histórico e busca uma interpretação de Foucault, dizendo que $o$ sujeito é formado pelas práticas que o constituem.

Pode-se considerar que a possibilidade do portador inscrever-se no social como sujeito requeira uma posição mais ativa, movida pelo desejo. Mas o desejo implica num endereçamento em direção a um outro, que poderá ou não acolhê-lo.

É interessante a relação que faz Foucault acerca da ligação do discurso com o desejo e com o poder. Traz uma contribuição da psicanálise, ao evidenciar que o discurso

não é simplesmente aquilo que se manifesta (ou oculta) o desejo; é, também, aquilo que é objeto do desejo (...) o discurso não é simplesmente aquilo que traduz as lutas ou os sistemas de dominação, mas aquilo por que, pelo que se luta, o poder do qual nos queremos apoderar (FOUCAULT, 1996, p. 10).

Foucault refere, a respeito do discurso do louco, que este não pode circular como o dos outros e que, historicamente, é através de suas palavras que se reconhece sua loucura. Poderíamos nos perguntar qual o lugar da palavra, por exemplo, do portador de defi- ciência mental, tradicionalmente apontado como imbecil, idiota, retardado, débil mental... ou mesmo louco - embora a condição da loucura não esteja associada, necessariamente, a este quadro - e de que maneira poderá compartilhar - apoderar-se? - dos significantes do discurso social.

Uma questão que se faz fundamental é a de examinar o efeito causado pela diferença que o portador porta em seu corpo e que se reflete enquanto imagem na sua relação social. Aqui, faremos algumas digressões na busca de recursos teóricos para avançar nossas indagações, começando por abordar alguns elementos conceituais de Walter Benjamim.

Jeanne-Marie Gagnebin (1994), em seu Prefácio - Walter Benjamin ou a história aberta aponta o conceito de experiência (Erfahrung) como central na obra deste autor, o qual parece retomar, em diferentes momentos, este conceito, buscando sua ampliação. Benjamim revela-se sensível aos fenômenos humanos de seu tempo, apontando alguns sintomas sociais do mundo capitalista moderno, dentre eles, o enfraquecimento da experiência numa esfera da transmissão , passível de ser contada (Erfahrung), em detrimento daquela experiência vivida, própria de um sujeito solitário (Erlebnis), resultante da desagregação e o esfacelamento social.

Walter Benjamim, ao ouvir (e experienciar) as dores de sua contemporaneidade consegue, ao mesmo tempo, analisar e identificar "brechas" capazes de restituir um lugar de sujeito no laço coletivo, lado a lado à emergência de um sujeito isolado como efeito de uma perda dos laços de tradição e de memória comuns. Cada época histórica , de acordo com Benjamim, abre a possibilidade de ser contada em diferentes versões, contextualizando-se às suas facetas político/sociais que tendem a determinar o que pode ser lembrado e o que deve produzir esquecimento.

Gagnebin lembra que Benjamin tem o escritor Franz Kafka como o maior narrador moderno, cuja obra representaria uma experiência única, a da perda da experiência, da desagregação da tradição e do desaparecimento do sentido primordial (GAGNEBIN, 1994, p. 18). Benjamin trabalha a idéia da transmissão prevalecendo à consistência da verdade, onde

a tradição torna-se autônoma em relação ao sentido inicial no qual, originalmente, tinha suas raízes. Esse movimento é, profundamente, o da metáfora que parte do sentido "literal" mas acaba abandonando-o e até, de transposição em transposição, prescindindo dele (Gagnebin, op.cit., p. 19).

Kafka apresenta muitos de seus personagens sob forma de animais, para deles recuperar o que fora 
esquecido e o esquecimento não é nunca um esquecimento individual, de acordo com Benjamin (1994). E estes animais se mostram em seu aspecto deformado, distorcido, tais como Gregor Samsa e Odradek, que ocupam lugares de descaso, ou melhor, um nãolugar, pois não têm paradeiro nem destino, talvez nem a morte sirva como meta. Benjamin refere-se a Odradek como o aspecto assumido pelas coisas em estado de esquecimento. Elas são deformadas. Outra interpretação benjaminiana expressa que, em Kafka, as costas que importam, pois vários de seus personagens têm nas costas o receptáculo das inscrições e da dor. E diz que a idéia de estar carregado tem relação com a de esquecer (BENJAMIN, 1994, p. 158-9).

Não podemos nos abster de pensar, a partir destas considerações, a questão do portador e seu lugar de esquecido, de excluído, no social. No dicionário encontramos, como uma das definições para a palavra portador, aquele que porta ou conduz, ou traz consigo, ou em si ou carregador (FERREIRA, 1999, p. 1612). Isso nos faz deslizar para a idéia de que $o$ portador porta/carrega a dor. Mas de que dor se trataria? Talvez seja possível pensar na dor da existência. Porém, todos compartilhamos desta mesma dor e, fazendo uso de uma expressão utilizada como referência aos portadores de deficiência, somos todos "portadores de necessidades especiais", levando-se em conta nossas diferenças.

O termo deficiência remete às idéias de falta, falha, carência, imperfeição, defeito, insuficiência (FERREIRA, 1999, p. 614). E o que seria isso que faz laço e que, ao mesmo tempo, produz rechaço a partir da imagem de deformação do corpo que muitos portadores de deficiência carregam (portadores de síndromes, paralisia cerebral...)? Entendemos que uma pessoa com deficiência denuncia, com sua imagem, a imperfeição humana, na qual estamos todos incluídos.

Frente ao excesso produzido por sua imagem, nos deparamos com o conceito de choque, desenvolvido por Benjamin e apresentado por Buck-Morss (1996). O choque implicaria na percepção dos estímulos excessivos e na necessidade do sujeito de encontrar defesas para proteger a psique do trauma do choque perceptual. O sistema sinestésico estaria dirigido a esquivar-se dos estímulos, encontrando saídas que produzam sua anestética.

Poderíamos associar, neste ponto, o conceito de narcisismo, utilizado por Benjamin e referido por esta autora, a qual coloca que o narcisismo que desenvolvemos funciona como uma tática anestesiante contra o choque da experiência moderna... e revela que, na raiz da palavra narcisismo, encontramos a mesma raiz de narcótico, vocábulo significativo ao tratarmos do excesso de estímulos e da anestesis como forma de se defender do choque. Este enfoque nos faz pensar o lugar ocupado pelas pessoas que denunciam a fragmentação dos ideais de uma cultura, em nossa questão, do ideal de perfeição. A falta de igualdade ou semelhança - tem-se esta como uma das possíveis definições para o termo diferença - apóia-se, de modo fundamental, no plano da imagem, pois a imagem do outro (des)semelhante implicaria numa ruptura do ideal narcísico.

Frente ao "excesso", é preciso proteger-se deste "estímulo", afastando-o do campo de visão a fim de restaurar uma perfeição imaginária.

Não teríamos, aqui, um argumento para pensar a exclusão? Estas questões lançam alguns desafios na construção de espaços de inclusão ao portador de deficiência, pois convoca a sociedade a lidar com suas dores, remetendo seus cidadãos à condição de seres faltantes, imperfeitos, incompletos... E isto não nos parece uma tarefa fácil, justamente numa época em que mergulhamos na cultura do narcisismo, expressão subjetiva da modernidade. Segundo Eizirik (2002, p. 45), esta imagem narcisista que foi abalada coloca a necessidade de sua reformulação, abrindo canais para a complexidade, a polifonia, a multiplicidade.

Visto o assunto numa ótica invertida, poderíamos nos perguntar, na relação do portador com a sociedade, que imagem lhe é retornada. Se, ao contrário, o que se encontra é uma defesa narcísica contra o "choque" da imagem de imperfeição, qual imagem retornaria ao portador diante do "grande espelho" - o olhar do outro? Se, de acordo com os significantes do discurso social, o que temos como valor é a imagem de um corpo perfeito onde as falhas precisam ser restauradas, qual o efeito subjetivo disso no sujeito portador? Talvez sua dor também precise ser anestesiada , a fim de preservar este ideal de perfeição e assegurar um modo possível de relação social - o que não deixa de impor suas conseqüências.

Cláudia Perrone (2002, p.4-5), num texto chamado Um Olhar Capturado pela Intensidade - o Corpo e Walter Benjamin coloca que o corpo não está à disposição de si mesmo. O saber o que se é se dilui em uma plenitude de extensão infinita. A deformação revelaria uma verdade num sentido de reivindicação, idoneidade expressiva que quebra a hegemonia da palavra e da linguagem. Cita Moholy Nagy que, em 1947, escreveu que $A$ distorção pode ser uma visão em movimento, mais do que o rápido gesto das partes do corpo. Perrone também traz Picasso, ao apontar o fato deste artista procurar quebrar a coerência do corpo humano, capaz de realizar a dissolução do Um para potencializar o múltiplo.

Perrone traz a figura de um corpo explodido, pintado por Bacon, movido pela distorção, dizendo 
que os órgãos abrem-se para fora e avançam para o corpo social implodidos pelo silêncio da não identidade, revelando as ruínas de dentro (...) A distorção é a expressão de algo dividido desde o interior de si mesmo, é a transitoriedade (PERRONE, 2002, p. 6).

Benjamim procura ressaltar a importância da experiência ao supor que os excessos que produzem choque possam produzir memória ao deixar suas marcas, as quais terão sua expressão nos processos de subjetivação. Parece que são justamente as marcas que carregamos - e sua representação subjetiva - que possibilitam nossa constituição como humanos, diferenciando-nos pela singularidade e aproximando-nos pelo compartilhamento dos significantes da cultura, viabilizando o laço social.

Jacy Alves de Seixas coloca que temos a sensação de viver sob o império da memória e de seu correlato, o esquecimento. A memória dos excluídos estaria excluída do lugar de memória oficial, recalcada do reconhecimento social e da cidadania. Eizirik explica que

Os processos de exclusão são culturais, são acumulados, nunca vêm sozinhos; desenvolvem-se e se reproduzem através do tempo, por meio de um sem número de formas que se entrelaçam no tecido social e se movimentam através das instituições, dos regulamentos, dos saberes, das técnicas e dos dispositivos que se instalam na cultura (EIZIRIK, 2002, p. 45).

Seixas, inspirado em Benjamin, aponta que a reconstrução da história empreendida pela memória responde a demandas e interesses políticos. Diz que toda memória é criação do passado:

...uma reconstrução engajada do passado (muitas vezes subversiva, resgatando a periferia e os marginalizados) e que desempenha um papel fundamental na maioria como os grupos sociais mais heterogêneos apreendem o mundo presente e reconstroem sua identidade, inserindo-se assim nas estratégias de reivindicação por um complexo direito ao reconhecimento (SEIXAS, p. 42).

Segundo Seixas, um dos efeitos da apropriação da memória pela história

está na raiz de importantes movimentos identitários (sociais e/ou políticos) e da afirmação de novas subjetividades, de novas cidadanias. Responsável pelo resgate de experiências marginais ou historicamente traumáticas, localizadas fora das fronteiras ou na periferia da história oficial ou dominante (SEIXAS, p.43).

As considerações teóricas até então realiza- das nos dão margem para formularmos novos questionamentos: como "dar memória" ao esquecido, às coisas que não devem ser lembradas? Como recriar este aparato sensorial que "barra" e exclui os excessos, protegendo-se do choque/trauma anestesicamente - narcisicamente? Como transpor a experiência individual, vivida pelo portador, e compartilhá-la com o coletivo, produzindo um novo significado para essa experiência, encadeando-a num laço de transmissão? Como (re)construir um lugar na história, no corpo coletivo? Certamente que temos à nossa disposição muitos elementos para reflexão.

Vivemos num tempo em que, ao nos depararmos com os desafios da inclusão, o que passa pela convivência com as nossas diferenças, conforme Eizirick (2001), suas práticas precisam ser inventadas. Talvez a possibilidade de problematizar a exclusão, como a outra face da mesma questão, permita que possa surgir no espelho o reflexo de nossa própria imagem e que possamos nos apropriar do que é nosso enquanto sociedade.

Antônio Cândido, em um belo texto escrito em 1946, intitulado O Portador e publicado num posfácio às Obras Incompletas de Nietzsche, escreve: Há, com efeito, seres portadores, que podemos ou não encontrar, na existência cotidiana e nas leituras que subjugam o espírito. Quando isto se dá, sentimos que eles iluminam bruscamente os cantos escuros do entendimento e, unificando os sentimentos desparelhados, revelam possibilidades de uma existência mais real. Os valores que trazem, eminentemente radioativos, nos trespassam, deixam translúcidos e não raro prontos para os raros heroísmos do ato e do pensamento. Geralmente, ficamos ofuscados um instante quando os vemos e, sem força para os receber, tergiversamos e nos desviamos deles. A opacidade se refaz, então, a mediania recobra o domínio e só resta a lembrança, de efeitos variáveis. Os coevos lobrigavam chamas do inferno na barra da túnica de Dante; nos nossos olhos resta igualmente a nostalgia do reino perdido, como no soneto admirável de Antero de Quental:

$E$ assentado entre as formas imperfeitas, Para sempre fiquei pálido e triste. (CÂNDIDO, 1983, p. 415).

E conclui: Na nossa época, ao se abrir a primeira fase da história em que será preciso reorganizar o mundo sem apelo ao divino, o que se poderia dizer de melhor para instalar o homem na sua pura humanidade? (CÂNDIDO, 1983, p. 416). 


\section{REFERÊNCIAS:}

BENJAMIN, W. Obras escolhidas. Volume I. São Paulo, Brasiliense, 1994.

BUCK-MORSS, S. Estética e anestética: o "ensaio sobre a obra de arte" de Walter Benjamin reconsiderado. Travessia - Revista de Literatura $\mathrm{n}^{\circ} 33$. UFSC Ilha de Santa Catarina, Ago-Dez /1996, p. 11-41.

CÂNDIDO, A. Posfácio - O portador. In.: NIETZSCHE, F. W. Obras completas. São Paulo, Abril Cultural, 1983.

EIZIRIK, M. F. Educação e escola: a aventura institucional. Porto Alegre, AGE, 2001.

EIZIRIK, M. F. Michel Foucault: um pensador do presente. Ijuí, Ed. Unijuí, 2002.

FERREIRA, A. B. H. Novo Aurélio. Rio de Janeiro, Nova Fronteira, 1999.

FOUCAULT, M. A ordem do discurso. Aula Inaugural no Collége de France, pronunciada em 2 de dezembro de 1970. São Paulo, Edições Loyola, 1996.

LEI No 8.069 de 13 de julho de 1990.

LEI No 8.213 de 24 de julho de 1991.

LEI No 9.394 de 20 de dezembro de 1996.

LEI No 10.216 de 06 de abril de 2001.

PERRONE, C. Um olhar capturado pela intensidade. O corpo e Walter Benjamin. UFRGS, 2002.

SEIXAS, J. A. Percurso de memórias em terras de história: problemáticas atuais. Universidade Federal de Uberlândia.

Denise Teresinha da Rocha Quintão é psicóloga, especialista em Psicologia Organizacional e do Trabalho. Aluna do curso de licenciatura em Psicologia da UFRGS. O endereço eletrônico da autora é: quintao@cpovo.net

\section{Denise Teresinha da Rosa Quintão}

O "portador": o corpo, a imagem e o social.

Recebido: 3/06/2003

$1^{\text {a }}$ revisão: 23/09/2003

$2^{a}$ revisão: 15/09/2004

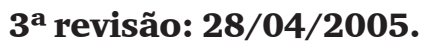

Aceite final: 2/05/2005 